\title{
La bande-son du township
}

\section{Culture cinématographique et urbanité sonore à Kinshasa et Johannesburg (années 1930-1950)}

Charlotte Grabli

Citer cet article : Grabli Charlotte (2021), « La bande-son du township. Culture cinématographique et urbanité sonore à Kinshasa et Johannesburg, 1930-1960 », Revue d'Histoire Contemporaine de l'Afrique, n², 18-41, en ligne. URL : https://oap.unige.ch/journals/rhca/article/view/02grabli

Mise en ligne : $1^{\text {er }}$ octobre 2021

DOI : https://doi.org/10.51185/journals/rhca.2021.e551

\section{Résumé}

Cet article étudie les cultures cinématographiques des townships de Kinshasa et Johannesburg des années 1930 aux années 1950, en mettant l'accent sur l'expérience des spectateurs et leur réception de la bandeson des films, deux aspects souvent négligés par les études sur le cinéma. Si Hollywood exerça une influence similaire dans ces deux villes, les spectateurs du quartier de Sophiatown, à Johannesburg, et de la «cité indigène » de Léopoldville (actuel Kinshasa), entretenaient un rapport radicalement différent aux dialogues et aux musiques de films. Examinant ces deux types de réception sonore, cet article analyse la relation complexe entre son, espace et politique de la fiction à l'époque coloniale et de l'apartheid, depuis les premières projections destinées aux publics africains jusqu'à la production de films populaires mettant en scène des acteurs locaux à la fin des années 1950, jusqu'à la destruction de Sophiatown et l'indépendance de l'indépendance du Congo en 1960.

Mots-clés : Johannesburg ; Léopoldville/Kinshasa ; culture cinématographique ; bande-son ; réception des films ; urbanité sonore ; histoire coloniale ; censure ; ségrégation 
Dans les années 1940 et 1950, les townships de Johannesburg et de Léopoldville (actuel Kinshasa) représentaient des "villes cinématographiques» par excellence ${ }^{1}$. À Sophiatown, le quartier de Johannesburg connu comme le principal centre de la vie culturelle et politique sudafricaine noire dans les années 1940 et 1950, Hollywood offrait à la fois une entrée dans un pays de « gangsters celluloïd » et un répit vis-à-vis des interdictions étouffantes de l'apartheid². Au même moment, les jeunes du mouvement «Bill »- du nom de l'un des héros des jeunes kinois, Buffalo Bill - déambulaient dans les quartiers de la cité de Léopoldville rebaptisés Kansas-City, Texas, Mexico ou Far West ${ }^{3}$. Dans ces deux villes se déployaient un sens du style montrant que les codes étaient faits pour qu'on en use et en abuse ${ }^{4}$. Cependant, si un rapide survol de ces cultures cinématographiques témoigne bien d'une même appropriation du lexique hollywoodien, il révèle aussi que les spectateurs congolais et sud-africains appréhendaient les bandes sonores des films de manière radicalement différente. Alors que le public de Johannesburg était captivé par les composantes auditives et orales des films, imitant les dialogues et chantant durant les projections de comédies musicales, celui de Léopoldville noyait le son des films dans un flot de commentaires bruyants. En historicisant ces deux modes de réception sonore, cet article interroge la manière dont les citadins de Léopoldville et de Johannesburg usaient différemment des sons et d'une certaine politique de la fiction pour s'approprier leur township.

À Johannesburg et Léopoldville - les pôles musicaux les plus influents du continent dans les années 1940 et 1950 -, la culture cinématographique des townships ne peut être pleinement comprise qu'en rapport avec le phénomène plus large d'urbanité sonore qui s'est développé avec les premiers mondes médiatiques et l'évolution des technologies musicales ${ }^{5}$. Dans les villes sud-africaines, ce phénomène remonte à l'avènement des films sonores (ou "parlants ») à la fin des années 1920. À Johannesburg et Léopoldville, de nouvelles formes médiatiques articulant cinéma et musique émergent après la Seconde Guerre mondiale avec la diffusion de postes de radio, d'appareils photographiques, de disques, de phonographes et de magazines présentant des stars locales et africaine-américaines.

Si ce décalage chronologique ne permet pas de mener une stricte étude comparative entre Johannesburg et Léopoldville, leurs townships gagnent à être explorés en tant qu'espaces musicaux et cinématographiques, du point de vue des auditeurs. Pour ce faire, je m'intéresserai aux différences et aux similitudes entre les usages de la bande sonore des films dans la cité de Léopoldville et à Sophiatown. Que révèle, en effet, la réception des dialogues, des musiques et des dispositifs sonores de projection de films sur l'évolution du rapport des citadins congolais

\footnotetext{
${ }^{1}$ Ici la « ville cinématographique » ne renvoie pas seulement aux représentations filmiques des townships, mais aussi à l'influence du cinéma sur le champ sonore et visuel des cultures urbaines. Pour une étude des interconnections entre la ville et l'écran, voir Clarke David B. (dir.) (1997), The Cinematic City, London, New York, Routledge.

2 Nixon Rob (1994), Homelands, Harlem, and Hollywood, London, New York, Routledge, p. 31.

3 Dans cet article, j'utilise "township » comme un terme générique se référant aux zones urbaines où les Africains étaient autorisés à vivre, bien qu'il ne s'applique pas légalement aux freehold locations comme Sophiatown ni à la " cité indigène » de Léopoldville. Je privilégierai par ailleurs le terme " cité », le diminutif communément employé pour designer la " cité indigène ». Sur les Bills et les noms de rue, voir Sesep N'Sial Bal-Nsien (1990), Langage, normes et répertoire en milieu urbain africain : l'indoubill, Quebec, Laval University, pp. 30-31; Gondola Charles-Didier (2016), Tropical Cowboys: Westerns, Violence, and Masculinity in Kinshasa, Bloomington, Indiana University Press.

4 Hebdige Dick (2008), Subculture: The Meaning of Style, London, New York, Routledge, p. 101.

5 Grabli Charlotte (2019), "La ville des auditeurs : radio, rumba congolaise et droit à la ville dans la cité indigène de Léopoldville (1949-1960) », Cahiers d'études africaines, 233(1), pp. 9-45.
} 
et sud-africains à la fiction? Dans quelle mesure l'appropriation, ou au contraire, le rejet des dimensions auditives et orales des films, peuvent être considérés comme des tactiques développées par les spectateurs en réponse à la censure et à la régulation de l'espace cinématographique ? En répondant à ces questions, j'accorderai une attention particulière à la manière dont l'événement cinématographique se développait en lien avec le sentiment croissant de souveraineté culturelle dans la cité de Léopoldville, à la veille de l'indépendance (30 juin 1960), et à Sophiatown, jusqu'à l'expulsion de ses habitants. La destruction ce quartier cosmopolite, annoncée en 1953, se déroula graduellement de 1955 à 1962. Elle représente un événement symptomatique de la nature de l'apartheid et demeure l'un des chapitres les plus sombres de l'histoire contemporaine de l'Afrique du Sud'.

Cette recherche s'appuie sur une longue tradition d'histoire urbaine et sociale qui a étudié les mondes musicaux et cinématographiques africains en mettant en valeur la créativité des citadins et leurs manières d'imprégner l'espace urbain de musiques, d'imaginaires, d'esthétiques et de plaisirs défiant les géographies raciales à l'époque coloniale et de I'apartheid7. Des recherches récentes sur le cinéma commercial et le public urbain en Afrique de l'Ouest et en Tanzanie ont ainsi illustré les immenses variations des cultures cinématographiques entre les pays africains, les villes et les petites villes, ceci tout en montrant la façon dont les citadins y sont devenus de grands amateurs de cinéma au début du vingtième siècle $^{8}$. Dans le cas de Léopoldville, Charles-Didier Gondola a bien montré comment les westerns hollywoodiens « ont donné lieu à une culture de la liminalité, à partir de laquelle les jeunes ont occupé et pris en charge les angles morts et les interstices créés par la négligence coloniale ${ }^{9}$ ». II montre par ailleurs que, contrairement à l'Afrique du Sud, Hollywood exerçait peu d'influence sur la musique moderne congolaise de Léopoldville (mieux connue sous le nom de « rumba congolaise ») qui s'inspirait moins des films que des disques de musique afrolatine depuis les années 1930.

Afin de mieux comprendre comment la fiction et l'imagination deviennent des questions politiques clés à l'époque coloniale, cet article s'appuie également sur les études des médias et de la réception des films qui s'écartent d'une approche visuelle pour privilégier l'analyse du son $^{10}$. Comme je l'ai montré ailleurs à propos de la radio dans la cité de Léopoldville dans les années 1950, étudier la manière dont les auditeurs détournent les médias, initialement considérés comme des instruments de propagande coloniale, ouvre de nouvelles voies pour

\footnotetext{
${ }^{6}$ Coplan David B. (2007), In Township Tonight!: Three Centuries of South African Black City Music and Theatre, Auckland Park, Jacana Media, p. 8.

7 Voir par exemple Ibid et Ansell Gwen (2004), Soweto Blues: Jazz, Popular Music, and Politics in South Africa, New York, Continuum. ${ }^{8}$ Voir Goerg Odile (2015), Fantômas sous les tropiques : aller au cinéma en Afrique coloniale, Paris, Vendémiaire ; Fair Laura (2018), Reel Pleasures: Cinema Audiences and Entrepreneurs in Twentieth-Century Urban Tanzania, Athens, Ohio University Press. Voir aussi l'étude pionnière de Haffner Pierre (1978), Essai sur les fondements du cinéma africain, Abidjan, Nouvelles Éditions Africaines; et Forest Claude (2021), "Les films à l'affiche dans les salles africaines Secma-Comacico (1960-1961) », Revue d'histoire contemporaine de l'Afrique, 1, en ligne. URL : https://oap.unige.ch/journals/rhca/article/view/01.forest (consulté le 4 août 2021).

9 Gondola, Tropical Cowboys..., op. cit., p. 3 ; Sur le contexte musical, voir du même auteur (2014) «Popular Music, Urban Society, and Changing Gender Relations in Kinshasa, Zaire (1950-1990) » in M. Grosz-Ngate et O. Kokole (dir.), Gendered Encounters: Challenging Cultural Boundaries and Social Hierarchies in Africa, New York, Routledge, pp. 65-84.

${ }^{10}$ Voir Chion Michel (1999), The Voice in Cinema, New York, Columbia University Press; Majumbdar Neepa (2001), « The Embodied Voice: Song Sequences and Stardom in Popular Hindi Cinema », in P. Wojcik et A. Knight (dir.), Soundtrack Available: Essays on Film and Popular Music, Durham, Duke University Press, pp. 161-182 ; Larkin Brian (2008), Signal and Noise: Media, Infrastructure, and Urban Culture in Nigeria, Durham, Duke University Press ; Dovey Lindiwe et Impey Angela (2010), « African Jim: Sound, Politics, and Pleasure in Early "Black" South African Cinema », Journal of African Cultural Studies, 22(1), pp. 57-73.
} 
mettre en évidence les liens sociaux et politiques entre le son et l'espace dans les townships ${ }^{11}$. Le domaine sonore représente de surcroît un sujet de recherche fascinant pour l'étude du cinéma en raison de sa double capacité à diffuser l'événement cinématographique à travers la culture urbaine et, en retour, infuser le cinéma avec des éléments du paysage sonore de la ville $^{12}$. Je m'appuierai ici sur les différentes qualités du son pour retracer la construction historique de l'événement cinématographique - un événement composé de diverses performances, se déroulant à la fois dans la salle et à l'écran - depuis ses origines au Congo belge et en Afrique du Sud jusque dans les années 1950. Cette période, qui englobe la production des premiers films mettant en scène des acteurs africains, permet de suivre les multiples allers-retours des sons des films entre les cinémas et la rue.

Cet article analyse deux films populaires mettant en scène des acteurs africains Matamata et Pilipili et Jim Comes to Jo'burg - ainsi que la presse de l'époque, des mémoires de journalistes, des entretiens de spectateurs sud-africains et quelques archives coloniales sur le cinéma. À la fin des années 1950, la presse coloniale et la presse « évoluée » (la bourgeoisie congolaise émergente) publiait régulièrement des articles sur la culture cinématographique de la cité. De nombreux auteurs sud-africains, notamment d'anciens journalistes du magazine Drum, un espace d'expression majeur pour une nouvelle génération d'écrivains et photographes noirs créé en 1951, évoquent l'expérience des spectateurs dans leurs mémoires, offrant des descriptions mêlant l'imagerie du film noir à des réflexions plus profondes sur les liens sensuels, esthétiques et émotionnels entre Sophiatown et les habitants.

\section{Léopoldville : qui contrôle la bande-son ?}

\section{"Nous bannirons les rêves": le système du commentaire en direct dans le Congo colonial}

La tentative du gouvernement de standardiser la projection des films dans tout le Congo belge, ainsi que le système de commentaire en direct qui faisait partie intégrante de ce processus, sont des éléments clés pour comprendre la réception des films à Léopoldville. Depuis le milieu des années 1940, l'expérience cinématographique congolaise était façonnée par une grande diversité de productions culturelles incluant les films muets de Charlie Chaplin, les films de Tarzan, les westerns qui inspiraient les bandes de jeunes comme les Bills, et les films éducatifs racistes réalisés dans la colonie ${ }^{13}$. À la fois projetés dans les centres urbains et les zones rurales, ces films étaient produits depuis l'après-guerre par le gouvernement et une poignée de missionnaires catholiques qui possédaient un équipement professionnel (pellicule $35 \mathrm{~mm}$ ). En 1950, 27 films conçus " dans le décor et avec des acteurs congolais ${ }^{14}$ », venaient compléter la filmothèque du gouvernement qui comptait déjà 1600 films, dont 1000 parlants et une

\footnotetext{
11 Grabli C., « La ville des auditeurs... », art. cité.

12 Altman Rick (1992), Sound Theory, Sound Practice, London; New York, Psychology Press, p. 14.

13 Pour un aperçu des films introduits aux publics africains au Congo Belge, voir Ramirez Francis et Rolot Christian (1985), Histoire du cinéma colonial au Zaire, au Rwanda et au Burundi, Bruxelles, Musée royal de l'Afrique Centrale ; Van Schuylenbergh Patricia (2021), "Le Congo belge sur pellicule: Ordre et désordres autour d'une décolonisation (ca. 1940- ca. 1960) », Revue d'histoire contemporaine de l'Afrique, 1, en ligne. URL : https://oap.unige.ch/journals/rhca/article/view/01.vanschuylenbergh (consulté le 4 août 2021) ; Gondola C. D., Tropical Cowboys..., op. cit.

14 Capelle Emmanuel (1947), La cité indigène de Léopoldville, Élisabethville, CEPSI, p. 80.
} 
centaine de films en couleurs achetés en Europe, au Canada, aux États-Unis et en Rhodésie du Nord et du Sud (aujourd'hui Zambie et Zimbabwe) ${ }^{15}$.

À l'instar de cette filmothèque, le dispositif de projection était destiné à des publics considérés comme vulnérables, sur le plan cognitif et culturel ${ }^{16}$. Les missionnaires parcourant le Congo belge constataient que les projections devaient être très courtes et abondamment commentées en langue locale - « sans cela, les Noirs confondent les scènes qu'ils ont vu défiler, et restent parfaitement incapables d'en tirer la leçon ${ }^{17}$ ». Sous leur influence, le système du commentaire en direct s'imposa, prenant pour modèle l'empire britannique où on l'estimait utile pour façonner et contrôler la réception de publics polyglottes ${ }^{18}$.

Lorsque les projectionnistes belges commencèrent à organiser des projections dans les zones rurales, ils utilisaient un microphone intégré aux 15 camionnettes de cinéma commandées aux Britanniques ${ }^{19}$. À partir de 1945, le Service d'information envoyait des films, des programmes et des notes au responsable local de la projection dans les différentes régions - 105 programmes circulaient au Congo belge en 195020. Ils disposaient également de leur propre groupe mobile de projection, composé d'une camionnette, d'un groupe électrogène, d'un projecteur, d'un écran mobile et d'un amplificateur de son, adaptés au transport. Le chauffeur, l'électricien et le projectionniste congolais étaient accompagnés d'un Européen "présence indispensable »- qui assurait le "commentaire adéquat » dans les langues vernaculaires locales ${ }^{21}$. De caractère rudimentaire, ce commentaire était probablement traduit avec l'aide des membres de l'équipe, ou d'un employé sur place, si ces derniers ne connaissaient pas la langue.

Dès 1944, le système du commentaire en direct prévaut également à Léopoldville où l'on entendait chaque semaine le commentateur sur les places de la cité où avaient lieu les projections publiques. Celui-ci s'exprimait en lingala, la lingua franca de Léopoldville et la langue de la rumba congolaise :

À l'aide d'un micro relié à l'amplificateur, un Européen remplaçait le commentaire du film par des explications en lingala. Connaissant bien la mentalité des Noirs, il pouvait aussi capter leurs réactions - imprévues, différentes d'un jour à l'autre et d'un quartier de la cité à l'autre - et rectifier aussitôt les erreurs ou attirer l'attention sur le détail important. ${ }^{22}$

Au milieu des années 1950, le commentateur était devenu une présence centrale dans l'événement cinématographique à Léopoldville. Des réalisateurs religieux comme l'abbé Cornil commencent à confier le commentaire à des « narrateurs » africains, imitant la Colonial Film Unit (CFU) de l'empire britannique, où des commentateurs locaux étaient engagés pour

\footnotetext{
${ }^{15}$ Anonyme, «Le rôle didactique de la cinéscopie », Congopresse, $1^{\text {er }}$ juin 1951.

16 Sur ce discours, éminemment politique, produit dans l'empire britannique à la fin des années 1920, voir Burns James (2002), Flickering Shadows: Cinema and Identity in Colonial Zimbabwe, Athens, Ohio University Press, pp. 37-59.

17 Paul Coppois, «Le cinéma pour indigènes au Congo belge », Congopresse, 15 novembre 1947.

18 Burns J., Flickering Shadows..., op. cit., p. 109 ; Bouchard Vincent (2010), "Commentary and Orality in African Film Reception », in M. Saul et R. Austen (dir.), Viewing African Cinema in the Twenty-First Century: Art Films and the Nollywood Video Revolution, Athens, Ohio University Press, p. 96.

19 Paul Coppois, "Le cinéma pour indigènes au Congo belge », art. cité.

${ }^{20}$ Anonyme, «Le rôle didactique de la cinéscopie », art. cité.

21 lbid.

22 Paul Coppois, « Le cinéma pour indigènes au Congo belge », art. cité.
} 
améliorer la prononciation du scénario et son impact sur le public ${ }^{23}$. Cependant, I'abbé Cornil ne laissait pas, comme la CFU, ces narrateurs organiser les séances de cinéma sans supervision directe. II fournissait à ses employés les sous-titres du film, des indications sur les passages à commenter, puis observait les réactions du public durant la séance. Là où l'abbé notait des flottements, il ajustait les commentaires afin d'atteindre l'idéal d'une "projection de film religieux dans un silence absolu ${ }^{24}$ ».

Une telle régulation impliquait un contrôle de la temporalité de la projection, régulièrement interrompue par des entractes au cours desquels «l'Européen rappelle et résume ce qu'on vient de voir, puis explique ce qu'on va voir ensuite ${ }^{25} »$. La conception des films répondait à la même logique, le réalisateur jugeant que le « cerveau encore frustre » des spectateurs leur rendait incompréhensibles les techniques comme le fondu-enchaîné et les ellipses : " Il faut aux Noirs des séquences lentes, des "gros plans" suggestifs, une action d'une simplicité élémentaire ${ }^{26} »$. Un autre cinéaste influent, le père Alexandre Van den Heuvel, cherchait à standardiser cette production cinématographique en insistant sur l'importance d'une structure temporelle linéaire. Les scènes devaient apparaître chronologiquement, sans retour en arrière ni saut dans le temps : "On bannira les rêves. L'idéal est un film où tout se passe en une journée ${ }^{27}$ ». En niant la capacité des spectateurs à savoir qu'ils se trouvaient au cinéma, c'est-à-dire absent de l'écran, en entier du côté de l'instance-percevante, cette vision paternaliste leur contestait un savoir «sans lequel aucun film ne serait possible ${ }^{28}$ ». Outre la prohibition des ressorts cinématographiques associés au plaisir filmique, le commentaire en direct avait un rôle central dans la déconstruction des potentialités de la fiction - pour que le message passe, prescrivait Van den Heuvel, « il ne faut guère avoir peur de déflorer l'intérêt ${ }^{29}$ ».

\section{Restaurer la fiction : jets de pierre et ivresse westernienne}

Dans une métropole comme Léopoldville, où la jeunesse était amatrice de westerns, ces films coloniaux et la réglementation de l'espace cinématographique apparaissaient en nette contradiction avec l'évolution de la culture cinématographique. Dans les années 1940, les foules nombreuses qui assistaient aux projections en plein air avaient encouragé la construction de salles privées. Dès 1944, Jean Hourdebise, un entrepreneur sensible aux cultures urbaines congolaises, demande aux autorités la permission d'ouvrir la première salle destinée à un public congolais ${ }^{30}$. Hourdebise ouvrira plusieurs salles, dont le célèbre cinéma

\footnotetext{
23 Burns J., Flickering Shadows..., op. cit., pp. 109-112 ; Rice Tom (2016), "'Are You Proud to Be British?': Mobile Film Shows, Local Voices and the Demise of the British Empire in Africa », Historical Journal of Film, Radio and Television, 36(3), pp. 331-351. Sur Cornil, voir aussi Van Schuylenbergh P., «Le Congo belge sur pellicule... », art. cité.

24 Bouchard V., "Commentary and Orality in African Film Reception... », art. cité., p. 99.

25 Paul Coppois, "Le cinéma pour indigène au Congo belge », art. cité.

26 Ibid.

27 Van den Heuvel Alexandre (1958), "Convient-il de faire du "film pour Africains" ? ", Rencontres internationales "Le cinéma et I'Afrique au sud du Sahara » à I'Exposition universelle de Bruxelles. Voir aussi Burns J., Flickering Shadows..., op. cit., p. 52.

28 Metz Christian (1977), Le signifiant imaginaire : psychanalyse et cinéma, Paris, Union générale d'éditions, pp. 68-69.

${ }^{29}$ Van den Heuvel A., « Convient-il de faire... », art. cité.

30 Hourdebise était connu dans la cité comme le fondateur de Radio Congolia, la première station à diffuser de la musique urbaine congolaise et des informations en quatre langues africaines. Archives africaines du Ministère des affaires étrangères de Belgique (AAMAEB), Gouverneur général, 16739 Léopoldville, Instructions divers, 1943-1949, Arrêté 531 du 3 août 1944 règlementant la consommation d'alcool.
} 
Albertum, appelé le Palladium après 1968 ${ }^{31}$. La plupart de ces cinémas (deux existaient en 1950, six en 195432) n'avaient rien de confortable. En 1958, Présence congolaise déplorait ainsi que les projections aient souvent lieu dans des maisons en construction, sans fenêtres ni portes, et " des bars à ciel ouvert où pendant la saison sèche on grelotte de froid ${ }^{33}$ ».

Lorsque le premier grand cinéma acceptant le public africain ouvrit ses portes en 1950 (une salle en plein air pouvant accueillir 1500 spectateurs), il devint un espace essentiel de l'urbanité congolaise comme le révèle le paysage sonore de la cité à l'époque: "Le soir, montent les acclamations des gens du stade, fusent les rires du public devant les films, nasillent les phonos au fond des bars, glapissent les trompettes des dancings ${ }^{34}$ ». Comme le futur directeur de «Radio Congo belge pour Africains » (1955-1957), André Scohy, le suggère ici, les mondes sonores, animés par les spectateurs, les barmen, les musiciens et les auditeurs, constituaient le premier vecteur et symbole de l'urbanité.

Cependant, contrairement au goût pour la rumba congolaise que partageaient toutes les catégories sociales du township, le cinéma était soumis à des logiques de distinction culturelle. Patronnés par les missionnaires et les fonctionnaires coloniaux, les ciné-clubs comme le CinéForum Baudouin proposaient des sélections alternatives aux programmes jugés médiocres des salles commerciales. L'élite congolaise préférait ces clubs aux salles de cinéma européennes, où elle était pourtant admise, en raison de l'hostilité des spectateurs et des patrons belges qui leur causait de "profondes blessures», comme s'en inquiétait le futur leader de I'indépendance Patrice Lumumba en $1955^{35}$. Les ciné-clubs présentaient de surcroît des sélections de films plus récentes là où il fallait généralement une année entière pour qu'un film commercial fasse le tour du circuit colonial, des projections pour les Européens aux séances privées des évolués, et enfin aux salles de cinéma moins lucratives ${ }^{36}$.

Tant les cinémas commerciaux que les ciné-clubs formaient des espaces où les spectateurs pouvaient restaurer le potentiel subversif de la fiction dans le contexte colonial. Dans les villes, ces séances acclamées s'établissaient en rupture avec celles des cinémas mobiles contrôlées par le système du commentaire en direct. Durant les projections à l'intérieur du territoire, il arrivait même que les spectateurs bombardent à coup de pierres l'écran de fortune dressé à l'orée de la forêt ${ }^{37}$. À Léopoldville également, l'abbé Cornil déclarait en 1957 ne plus vouloir donner de séances dans le quartier de Kitambo (Léo II) à la suite d'incidents : «Accueil désagréable, spectateurs mécontents, jets de pierre, etc. ${ }^{38}$ ". À l'instar des voitures européennes, fréquemment lapidées lors de leur passage dans les quartiers ségrégués ${ }^{39}$, les

\footnotetext{
31 Otten Rik et Bachy Victor (1984), Le cinéma dans les pays des grands lacs : Zaire, Rwanda, Burundi, Paris, L'Harmattan, p. 29.

32 Gondola C. D., Tropical Cowboys..., op. cit., p. 60.

33 Présence congolaise, 13 septembre 1958.

34 André Scohy, «Amusements congolais à Léopoldville », Congopresse, $1^{\mathrm{er}}$ décembre 1950.

35 Patrice Lumumba, «À propos de l'accès des Congolais dans les établissements publics pour Européens », La voix du Congolais, octobre 1955

36 Gondola C. D., Tropical Cowboys..., op.cit., pp. 60 et 214.

37 Scohy André (1958), "L'action du gouvernement général du Congo belge dans l'éducation des masses par le cinéma », in Rencontres internationales « Le cinéma et l'Afrique au sud du Sahara » à l'Exposition universelle de Bruxelles, pp. 76-78.

38 Anonyme, "À propos des séances de cinéma de l'abbé Cornil », Présence congolaise, 5 juillet 1958. La propagande religieuse pouvait être une des raisons du rejet. Une année plus tôt le jeune journaliste Joseph-Désiré Mobutu se faisait l'écho des plaintes des Congolais face aux projections de films éducatifs uniquement "bons pour les catéchumènes et les élèves d'école primaire », dans Actualités africaines, 16 mai 1957.

39 Anonyme, Présence congolaise, 7 février 1959.
} 
projections usant de dispositifs coloniaux comme le commentaire en direct étaient, à la veille de l'indépendance, perçues comme un symbole de la domination européenne.

Allant en ce sens, les films réalisés par les autorités coloniales qui étaient diffusés avant les séances de western dans les salles commerciales de Léopoldville, suscitaient le malaise des spectateurs. Connu pour être offensé par les films stéréotypés sur la vie dans la brousse et les films dits "d'exploration africaine », ce public avait du mal à comprendre ces court-métrages d'une minute - «ces films les rendent même nerveux ${ }^{40}$ ». À la fin des années 1950, le cinéaste français Jean Rouch cherche à expliquer cette hostilité dans le contexte ouest-africain: "L'Africain croit absolument ce qu'il voit sur l'écran. Pour les films réalisés en Afrique, sa réaction est souvent très violente. Le plus souvent, les Africains nous reprochent de leur montrer non pas comme ils sont mais comme nous voudrions qu'ils fussent ${ }^{41}$ ». Si ce rapport "absolu » à l'image ne relevait pas d'une croyance - dans le vocabulaire de la jeunesse congolaise, les termes "cinéma » et "bobine » étaient synonymes de mensonge et de supercherie ${ }^{42}$-, il est intéressant de noter que, dans les années 1950, les publics des zones rurales et urbaines s'insurgaient contre les représentations cinématographiques coloniales sur une grande partie du continent. Ces films véhiculaient en effet des caricatures invraisemblables, obligeant les spectateurs à se reconnaître dans des personnages les singeant grossièrement, tout en les représentant dans des films vidés de leur potentiel fictionnel.

L'observation des séances de western montre comment le public urbain rompait avec les logiques cinématographiques coloniales. Dans ses souvenirs, le journaliste Molei Kolonga décrit le déchaînement déclenché par le début du film :

À la première image du cow-boy, un ouragan d'applaudissements, une explosion de voix et des sifflements montent de la salle. Le dialogue sonore des films est englouti par les hurlements de spectateurs déchaînés, debout, qui, tantôt réclament davantage d'actions violentes, tantôt montés sur les sièges, poings fermés, se ruent sur des adversaires invisibles. L'ivresse westernienne achève ainsi de consumer cette jeunesse qui ne vit désormais que dans la peau d'un Pecos Bill, d'un Buffalo Bill et de tant d'autres cow-boys. Dès la sortie de la salle, ces groupes s'éparpillent dans tous les sens emportant au loin le message du Western - les Écumeurs du FAR WEST. ${ }^{43}$

Comme l'observait Georges Balandier en 1955 à Brazzaville, la capitale du Moyen-Congo voisin, cette réception des films montre l'intensité avec laquelle "le "jeu" est vécu ; à la fois en tant que jeu et en tant qu'enseignement ${ }^{44}$ ». Cette expérience était favorisée par l'effacement des dialogues qui transformait l'écran en miroir pour mieux laisser le mimétisme opérer dans le champ visuel. Cela était particulièrement adapté au genre de cinéma très codifié du western qui permettait aux spectateurs de suivre le scénario sans écouter les dialogues.

Contrairement à ce que suggère Gondola, ce brouhaha ne reflétait pas leur profonde compréhension du genre western ou une référence au langage non verbal du cow-boy qui

\footnotetext{
${ }^{40}$ Capelle E., La cité indigène..., op.cit., p. 80 ; Convents Guido (2006), Images \& démocratie : les Congolais face au cinéma et à l'audiovisuel: une histoire politico-culturelle du Congo des belges jusqu'à la République démocratique du Congo (1896-2006), KesselLo, Afrika Film Festival, p. 185.

${ }^{41}$ Rouch Jean (1958), "L'Africain devant le film ethnographique », in Rencontres internationales « Le cinéma et l'Afrique au sud du Sahara » à l'Exposition universelle de Bruxelles, pp. 92-94.

42 Sesep N., Langage, normes..., op. cit., p. 41.

${ }^{43}$ Molei Kolonga (1979), Kinshasa, ce village d'hier, Kinshasa, Sodimca, p. 214.

44 Balandier Georges (1985 [1955]), Sociologie des Brazzavilles noires, Paris, Armand Colin, p. 257.
} 
incarne « la physicalité du contrôle masculin sur les émotions ${ }^{45}$ ». La mise en valeur du son de la gâchette, du coup de feu et du cheval au galop révèle plutôt la centralité de la " panoplie sonore » du cow-boy dans l'expérience cinématographique du public et le plaisir mimétique des jeunes spectateurs. De cette manière, le public réduisait les westerns à des films muets qui, dans les premiers temps du cinéma, étaient toujours projetés avec de la musique, des effets sonores et la voix d'un commentateur ${ }^{46}$. Si l'on observe des phénomènes semblables aux débuts du cinéma européen ${ }^{47}$, et que l'on peut attribuer ce mode de réception à l'arrivée nouvelle du cinéma dans les villes africaines, il faut également le comprendre en regard du désir des spectateurs de commenter le monde colonial. En effet, outre l'action dans les westerns et les scènes de baisers, les apparitions du jeune roi belge Baudouin et l'image d'un Noir parmi les Blancs exaltaient aussi les spectateurs ${ }^{48}$. Comme dans le cas des films hollywoodiens, ces images étaient décontextualisées et appropriées par le public qui faisait de la séance de cinéma un forum, comme dans les années 1950 en Rhodésie du Nord et en Gold Coast (Ghana), ou encore dans le Protectorat tunisien ${ }^{49}$. Selon l'analyse des arts populaires de Karin Barber, ce type de forum dans lequel des situations et des interprétations sont proposées et éprouvées doit être considéré comme une réelle critique, au même titre que les contestations explicites de l'ordre colonial. C'est à partir de cette culture cinématographique quotidienne que «la conscience populaire se maintient et se renouvelle obstinément ${ }^{50}$ ».

Ce mode de réception doit donc être compris comme une autre des survivances du boniment à l'ère du cinéma parlant en Afrique ${ }^{51}$. En se faisant entendre par-dessus la voix des acteurs, les spectateurs s'érigeaient en unique producteur de discours. Le fait que ceux qui revenaient voir le même film plusieurs fois se proclamaient «commentateurs » suggère, en effet, une autre dimension du contrôle de la bande-son par les spectateurs ${ }^{52}$. Leurs improvisations et commentaires produisaient des interprétations multiples constituant un récit polyphonique qui venait se substituer aux voix du Service d'information du Congo belge. L'argot urbain se faisait l'écho de ce phénomène à travers une métaphore: l'auteur d'un discours interminable ou le discours lui-même étaient couramment surnommés «bande sonore ${ }^{53} »$.

\footnotetext{
45 Gondola C. D., Tropical Cowboys..., op. cit., p. 66.

46 C'était le cas avant la synchronisation du son et des images dans les premiers films «parlant » à la fin des années 1920. Voir Bottomore Stephen (2001), «The Story of Percy Peashaker: Debates about Sound Effects in the Early Cinema », in R. Abel et R. Altman (dir.), The Sounds of Early Cinema, Bloomington, Indiana University Press, p. 129.

47 Voir l'analyse de Metz dans Le Signifiant imaginaire..., op. cit., p. 124.

${ }^{48}$ Convents G., Images \& démocratie..., op.cit., p. 187.

49 Voir respectivement, Ambler Charles (2001), "Popular Films and Colonial Audiences: The Movies in Northern Rhodesia », The American Historical Review, 106(1), p. 96 ; Wright Richard (2008 [1954]), Black Power: A Record of Reactions in a Land of Pathos, New York, Harper \& Brothers, pp. 213-214; Corriou Morgan (2010), "Hourras, "hou hou" et tohu-bohu dans les cinémas de Tunisie à l'époque du protectorat ", in O. Carlier (dir.), Images du Maghreb, Images au Maghreb (XIxe - Xxe siècles). Une révolution du visuel ?, Paris, L'Harmattan, pp. 203-236.

${ }^{50}$ Barber Karin (1987), «Popular Arts in Africa », African Studies Review, 30(3), pp. 58 et 69.

51 Bouchard Vincent, Lacasse Germain et Scheppler Gwenn (2009), "Présentation. L'interrègne : I'héritage des bonimenteurs 》, Cinémas: revue d'études cinématographiques / Cinémas: Journal of Film Studies, 20(1), pp. 7-21.

52 Gondola C. D., Tropical Cowboys..., op. cit., p. 65.

53 Sesep N. (1990), Langage, normes..., op. cit., p. 40.
} 


\section{À Sophiatown : chanter en cœur avec les comédiens}

\section{Des écrans aux murs : les trajectoires de la fiction dans le township}

L'influence considérable d'Hollywood sur la culture urbaine sud-africaine a été largement documentée et représente l'un des traits essentiels de I'histoire des townships de Johannesburg. L'expérience cinématographique des spectateurs noirs (Africains, Indiens et les dits " coloured ») avait été façonnée par la longue évolution des structures du cinéma et de la ségrégation ${ }^{54}$. Au début du $X x^{\mathrm{e}}$ siècle, les Noirs sud-Africains étaient parfois autorisés à s'asseoir au balcon ou au fond des salles de cinéma, déjà répandues dans les zones urbaines. En 1936, quatre cinémas pouvaient projeter des films pour le public noir ${ }^{55}$. Avec la multiplication des salles à l'époque de l'apartheid, la fréquentation des cinémas devint l'un des aspects essentiels de l'expérience noire des townships, et ce, malgré l'application imprévisible et arbitraire de la censure. Les habitants de Johannesburg économisaient toute la semaine pour acheter leur place le samedi dans les salles «non blanches » telles que The Lyric, The Majestic, The Ritz, The Harlem, The Rio et, à Sophiatown, The Odin et The Balansky.

À Sophiatown, la culture cinématographique et la politique du son et de la fiction étaient remarquablement imbriquées. Le cinéma The Odin, où les logiques de plaisir musical et filmique se mêlaient à la résistance politique ${ }^{56}$, constituait le principal ancrage symbolique de ce township cinématographique. Alors que les films projetés dans ce cinéma nourrissaient les mises en scène quotidiennes de l'urbanité, la salle était en retour imprégnée de l'imaginaire de Johannesburg. Le poète et ancien chef de gang Don Mattera se souvenait en effet que l'on distinguait dans ce lieu, qui pouvait accueillir 1050 personnes, différentes sections désignées par des noms de quartiers : "Nous avions des sections comme "Fietas" et "Kliptown" dans le bioscope. Là où se trouvaient les bonnes places, il y avait "Parktown"57 ». Ces références spatiales différaient de celles inventées par les spectateurs des villes ouest-africaines qui se référaient généralement à l'imaginaire des westerns pour différencier les espaces sociaux à l'intérieur de la salle de cinéma. À Bamako, les places bon marché faisaient partie de «l'indiennat» («la place des Indiens ») tandis qu'à Conakry, les spectateurs distinguaient la place du cow-boy de celle de l'Indien. Quant aux Dakarois, ils appelaient l'avant de la salle le "parc à chèvres », par opposition aux sièges prévus pour les Européens et l'élite africaine ${ }^{58}$.

Ces expressions témoignent d'une perception, répandue dans les villes africaines, de la salle de cinéma comme un lieu d'échanges symboliques entre la fiction et la ville. Néanmoins, Sophiatown se distinguait par le devenir ouvertement politique de sa culture cinématographique et la façon dont les spectateurs transformaient l'oralité des films en une ressource pour lutter contre l'apartheid. II s'agissait d'une conception partagée par les publics noirs aux États-Unis comme l'illustre ce souvenir de l'auteur James Baldwin : « Mon premier

\footnotetext{
54 Voir Masilela Ntongela (1991), " "Come Back Africa" and South African film history », Jump Cut: a Review of Contemporary Media, 36, pp. 61-65.

55 Maingard Jacqueline (2007), South African National Cinema, London, Routledge, p. 67.

56 Coplan D., In Township Tonight!..., op. cit., p. 212.

57 Stein Pippa et Jacobson Ruth (dir.) (1986), Sophiatown Speaks, Johannesburg, Junction Avenue Press, p. 10. Sauf mention, les traductions sont de l'auteure.

58 Goerg O., Fantômas sous les tropiques..., op. cit., p. 175
} 
calcul conscient sur la manière de vaincre les intentions du monde à mon égard et à l'égard des miens a commencé ce samedi après-midi dans ce que nous appelions the movies ${ }^{59}$ ».

Illustration n 1 : «Sophiatown écrit son histoire sur les murs », Drum, 6 juin 1957

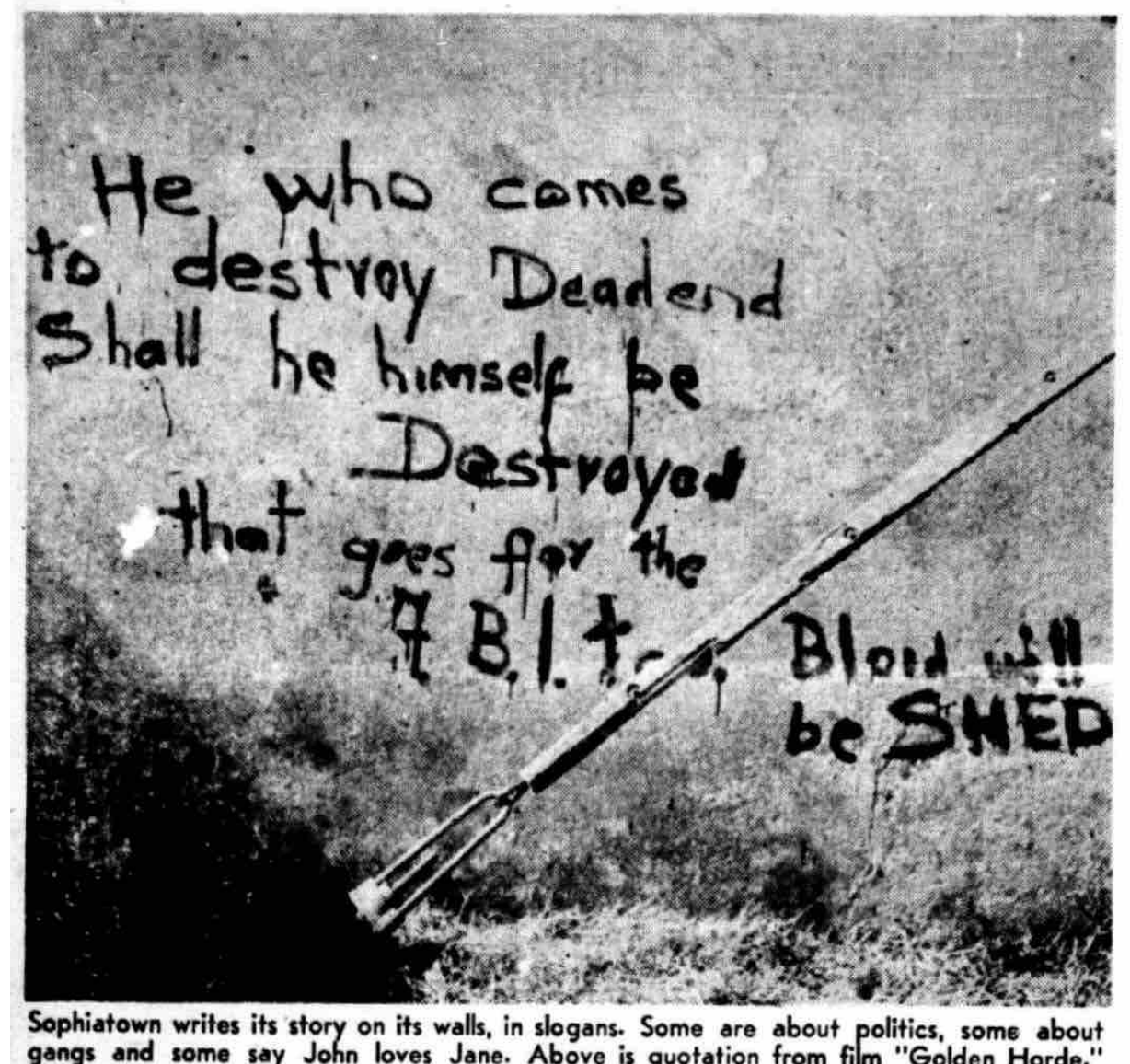

À mesure que la destruction de Sophiatown approchait, il existait des échanges fictionnels entre les cinémas et la ville, mais aussi entre les écrans de cinéma et les murs du township: "Nous avions I'habitude d'écrire à la peinture sur le mur : "Celui qui vient détruire Sophiatown sera lui-même détruit" car nous avions vu dans le film Summarkand [La Horde d'or (1951)] : "Celui qui vient détruire Samarkand sera lui-même détruit"60 ». Ainsi, les répliques des acteurs, détournées en slogans politiques, pouvaient, selon l'expression de Pierre Sansot, nouer «les consciences et les murs ${ }^{61} »$.

\footnotetext{
59 Baldwin James (1998 [1976]), "The Devil Finds Work », in T. Morrison (dir.), Collected Essays, New York, Literary Classics of the United States, p. 483. II souligne.

60 Stein P. et Jacobson R. (dir.), Sophiatown Speaks..., op. cit., p. 12.

61 Sansot Pierre (2004), Poétique de la ville, Paris, Payot \& Rivages, p. 384. Sur la manière dont Sophiatown « écrivait son histoire sur ses murs », voir Drum, 6 juin 1957.
} 
Maîtriser le jazz et la langue anglaise : le cinéma comme ressource cosmopolite et politique

L'expérience urbaine des spectateurs et leurs usages politiques du cinéma expliquent, dans une large mesure, leur appétence pour les musiques et les dialogues de film. L'élaboration conjointe des modes de réception des films et de la culture musicale apparaît dans les années 1930, à l'époque des westerns muets avec Hoot Gibson, Tom Tyler et Frankie Darro, et des comédies avec Charlie Chaplin, Harold Lloyd et Buster Keaton. Dans ses mémoires, Down Second Avenue, Ezekiel Mphahlele décrit ces longues projections, qui pouvaient comporter jusqu'à quatre films et un spectacle musical :

Un piano jouait un medley de morceaux bruyants qui, pourtant, faisait une musique de fond superbe. Les autres garçons me faisaient confiance pour lire tout haut les dialogues et les titres, afin qu'ils ne perdent rien de l'histoire [...]. J'arrivais à me faire entendre par-dessus le tapage de l'auditoire et les accords du piano qui jouait tout le long de la performance. ${ }^{62}$

Évoquant l'évolution sonore de l'événement cinématographique, l'auteur se remémore l'arrivée des « films parlant » en 1928 à Pretoria avec The Singing Fool où jouait Al Jolson : « Des foules enthousiastes se pressaient au cinéma pour voir la nouvelle merveille de l'histoire du film [...]. Al Jolson apportait la magie de l'époque : le film sonore ${ }^{63}$ ». Les projections sudafricaines étaient, en effet, basées sur le modèle européen où les films muets étaient accompagnés de concerts allant, selon le luxe de la salle, d'un orchestre complet à un piano honky tonk. Dans les villes sud-africaines, au même moment où la formule "PARLANT, CHANTANT, DANSANT » commençait à apparaitre sur toutes les devantures des cinémas ${ }^{64}$, la scène musicale du marabi et les soirées Concert and Dance florissaient. Dans ces dernières, la projection des films était suivie d'un spectacle de vaudeville qui se déroulait de $20 \mathrm{~h}$ à minuit, puis de danses jusqu'à $4 \mathrm{~h}$ du matin ${ }^{65}$. Pour la plupart des artistes jazz et vaudeville qui se produisaient dans les soirées Concert and Dance, le cinéma était une source d'émulation inépuisable, inspirant des nouveaux pas de danse, des musiques, des manières de jouer et de s'habiller6.

Compte-tenu de l'évolution musicale de ces différents types d'événements cinématographiques, il est significatif que les spectateurs aient conservé tout leur intérêt pour l'intrigue et les dialogues des films à l'ère du cinéma parlant. Parallèlement à des films comme Background to Danger (1943) qui inspiraient le «chic criminel » local67, d'autres productions comme The Raging Tide (1951) et Beginning of the End (1957) constituaient des ressources majeures pour l'apprentissage de la langue anglaise. « Nous nous asseyions et nous écoutions : c'est ainsi que nous apprenions. C'est de là que vient notre éducation, des films » se souvient

\footnotetext{
62 Mphahlele Ezekiel (1978), Down Second Avenue, Gloucester, Peter Smith, p. 40.

63 Ibid., pp. 82-83.

64 Ibid., p. 84

65 Au sens anglo-américain du terme, le vaudeville désigne un spectacle de variétés. Voir Ballantine C., " Concert and Dance... », art. cité, p. 122 ; Denis-Constant Martin (2008), « Our Kind of Jazz : musique et identité en Afrique du Sud », Critique internationale, 38(1), p. 100.

66 Ballantine C., « Concert and Dance... », art. cité, p. 131.

67 Nixon R., Homelands..., op. cit., p. 31.
} 
Mattera ${ }^{68}$. Parallèlement à l'influence britannique sur les classes moyennes noires éduquées dans les missions, Hollywood exerçait un attrait plus large, disséminant la culture états-unienne parmi toutes les classes sociales ${ }^{69}$. Dans ce contexte, l'avidité de l'auteur Mphahlele pour l'apprentissage de la lecture est révélatrice: « Je pouvais lire aussi vite que le tempo lent de la vie de l'époque l'exigeait. Je lisais et lisais jusqu'à la douleur. Mais je n'en tirais pas moins un plaisir immense. Et j'étais fier de vaincre mon retard ${ }^{70}$ ».

La perception auditive du cinéma semblait indissociable d'un processus d'apprentissage fondé sur le plaisir mimétique. Dans les années 1950, on observe également ce phénomène dans le monde musical de Johannesburg inspiré des comédies musicales et des films noirs mettant en scène des night-clubs, des casinos et des chanteuses ${ }^{71}$. Ceux-ci constituaient une part importante de la programmation cinématographique ; les performances de Lena Horne, Cab Calloway, Fred Astaire, Ginger Rogers, Ethel Walters et Bill Robinson étaient bien connues des Sud-Africains ${ }^{72}$. Notons que cette réception musicale des films avait émergé dès l'époque des premiers westerns. Contrairement à la culture cinématographique congolaise, il semble en effet que la figure du "cow-boy chantant», apparue au cinéma après la conversion d'Hollywood au son synchronisé dans les années $1920^{73}$, avait profondément marqué la culture des jeunes sud-africains, en particulier dans le Natal, une région à l'Est de l'Afrique du Sud. Selon l'anthropologue Absolom Vilakazi, dans les années 1920, les jeunes des zones rurales de cette région étaient nombreux à copier l'habillement et les manières de "umqhafi » (plur. abaqhafi) qui portait " un chapeau de cowboy et tenait une guitare, un concertina, ou un harmonica, qu'il emportait partout pour jouer de la musique gratuitement, pour tous ${ }^{74}$ ». Selon le chanteur de jazz David Serame, les comédies musicales faisaient une aussi forte impression sur les habitants de Sophiatown. Après les projections où ils avaient chanté en cœur avec les comédiens à l'écran, les jeunes spectateurs se regroupaient à la sortie du cinéma pour rejouer des films et chanter toute la bande-son ${ }^{75}$.

Le fait qu'Hollywood associait alors le statut des musiciens africain-américains à la valorisation de la race noire n'explique pas à lui seul ces modes de réception filmique. En effet, I'identification avec les interprètes noirs - que la plupart des études récentes soulignent ${ }^{76}$ n'était pas un phénomène univoque. Par exemple, I'un des plus célèbres compositeurs sudafricains, le trompettiste Hugh Masekela, choisit son instrument après avoir vu Kirk Douglas jouer le rôle du jazzman blanc «Bix » Beiderbecke dans Young Man with a Horn (1950). Dans ce film, la grande influence des musiciens noirs sur le développement stylistique de Beiderbecke se résume, de surcroît, à " un long apprentissage avec un seul personnage africain-américain, le trompettiste Art Hazard (Juano Hernandez) [...] [qui] finit par prononcer le discours obligatoire dans lequel l'élève blanc est félicité pour avoir surpassé son mentor ${ }^{77}{ }^{\prime}$.

\footnotetext{
68 Stein P. et Jacobson R. (dir.), Sophiatown Speaks..., op. cit., p. 12.

69 Nixon R., Homelands..., op. cit., p. 12.

70 Mphahlele E., Down Second Avenue..., op. cit., p. 40

71 Davis Peter (1996), In Darkest Hollywood: Exploring the Jungles of Cinema's South Africa, Athens, Ohio University Press, p. 23.

72 Coplan D., In Township Tonight!..., op. cit., p. 173.

73 Stanfield Peter (2002), Horse Opera: The Strange History of the 1930s Singing Cowboy, Urbana, University of Illinois Press.

74 Vilakazi Absolom (1965), Zulu Transformations: A Study of the Dynamics of Social Change, Pietermaritzburg, University of Natal Press, p. 76. Voir aussi Coplan D., In Township Tonight!..., op. cit., p. 113.

75 Dovey L. et Impey A., «African Jim... », art. cité, p. 59.

76 Voir par exemple Maingard J., South African..., op. cit., p. 84.

77 Gabbard Krin (1996), Jammin' at the Margins: Jazz and the American Cinema, Chicago, University of Chicago Press, pp. 71-82.
} 
Loin de s'identifier à une star noire des États-Unis, il est notable que Masekela appréciait, ou ignorait, la façon dont ce film aborde la question de l'influence des musiciens noirs sur le jeu des jazzmen blancs.

\section{Le township cinématographique à l'écran: Jim Comes to Jo'burg, Matamata et Pilipili}

Le succès du film Jim Comes to Jo'burg à la fin des années 1940 (également connu sous le nom d'African Jim), comme celui de la série comique destinée au public congolais, Matamata et Pilipili, dans les années 1950, illustrent bien la relation complexe des spectateurs avec les productions mettant en scène des acteurs noirs locaux. En effet, en Afrique du Sud, comme au Congo belge, un casting africain ne suffisait jamais à emporter l'adhésion du public. Nongogo, par exemple, une pièce de théâtre présentée au Bantu Men's Social Centre en 1959 était critiquée par « les non-Européens [qui] avaient l'impression que la vie dans les townships avait été déformée ${ }^{78} »$. Étant donné le rejet récurrent des représentations filmiques de l'Afrique, on peut s'interroger sur l'immense popularité de ces productions réalisées localement au Congo et en Afrique du sud. Avec ces films, quelle relation nouvelle émergeait entre la ville et les acteurs africains tels que la chanteuse glamour de Sophiatown, Dolly Rathebe ${ }^{79}$ ? Cette dernière partie propose d'y répondre en comparant l'accueil réservé à Jim Comes to Jo'burg et Matamata et Pilipili.

Le premier paradoxe du succès de Jim Comes to Jo'burg, réalisé en 1949 par deux immigrants britanniques en Afrique du Sud, Donald Swanson et Erica Rutherford, tient à son adhésion évidente à l'idéologie de l'apartheid. Le message défilant avant la séance mettait ainsi en perspective ce film destiné à un public africain : "C'est un film simple et son mélange pittoresque de naïveté et de sophistication est le véritable reflet de l'indigène africain dans une ville moderne ${ }^{80} »$. En tant que premier long métrage avec un casting noir sud-africain, Jim Comes to Jo'burg préfigurait les codes du «cinéma bantou » qui, suivant l'idéologie de l'apartheid, opposait le mode de vie rural et idyllique des « indigènes » à la ville moderne et corrompue.

\footnotetext{
78 The University of Witwatersrand Historical Papers, Johannesburg, AD1912 Press Cut 'Films entertainment', 1947-63, "Shebeens Are Never Like This", 1959.

${ }^{79}$ Fleming Tyler (2012), "Stars of Song and Cinema: The Impact of Film on 1950s Johannesburg's Black Music Scene », in T. Falola et T. Fleming (dir.), Music, Performance and African Identities, New York, Routledge, pp. 169-190 ; Coplan D., In Township Tonight!..., op. cit., p. 174.

${ }^{80}$ Bickford-Smith Vivian (2006), « How Urban South Africa Life Was Represented in Film and Films Consumed in South African Cities in the 1950s », Journal of Interdisciplinary Crossroads, 2(3), pp. 431-442.
} 


\section{Illustration $n^{\circ} 2$ : Affiche du film African Jim (1949) ${ }^{81}$}

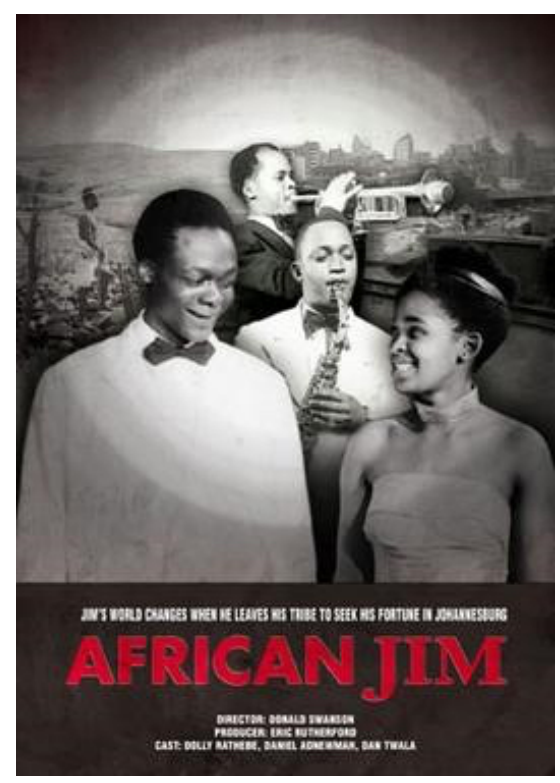

Néanmoins, tout en dépeignant le Johannesburg noir comme une ville dangereuse, celuici apparaissait comme un territoire musical cosmopolite. Le film faisait en effet partie d'une série commercialisée sous le nom de «All-African » (1950-1959) qui s'appuyait sur des groupes de jazz locaux et l'influence du vaudeville pour attirer un public noir ${ }^{82}$. La principale performance musicale de Jim Comes to Jo'burg était ainsi révélatrice de l'ambiguïté générée par ce type de film. Dans le rôle de Judy, la chanteuse résidente du club Ngoma, où Jim (joué par Daniel Adnewmah) est employé comme domestique, Dolly Rathebe chante : "Oh, je suis allée à Jo'burg, la Golden City; Oh, pourquoi suis-je allée là-bas ? Je suis loin de chez moi dans la ville de Jo'burg ». Cette chanson était une adaptation du titre populaire " / Lost my Sugar in Salt Lake City ${ }^{3}$ » tiré de Stormy Weather (1943); tout en incarnant la dichotomie portée par le "cinéma bantou », elle renvoyait à un film qui avait "électrisé » Sophiatown et façonné l'urbanité sonore locale, en particulier les manières de parler, la mode vestimentaire et les performances scéniques ${ }^{84}$.

Selon l'écrivain Can Themba, I'un des critiques les plus acerbes de l'époque, l'apparition de cette icône musicale à l'écran était le seul élément digne d'être mentionné :

Même les personnes pensant habituellement que le cinéma n'était pas un divertissement pour les gens convenables s'y rendirent par milliers pour voir Dolly Rathebe dans Jim Comes to Jo'burg [...]. C'était comme si l'Afrique avait été transportée dans le monde fascinant d'Hollywood. ${ }^{85}$

\footnotetext{
${ }^{81}$ Au premier plan : Daniel Adnewmah (Jim) et Dolly Rathebe (Judy). La légende orginale est " Jim's world changes when he leaves his tribe to seek his fortune in Johannesburg".

82 Maingard J., South African..., op. cit., p. 89.

${ }^{83}$ Le titre composé par Leon Rene et Johnny Lange en 1942 avait pour paroles originales : " / lost my sugar in Salt Lake City; Oh, why did I go there?; I should have stayed down in New Orleans; And never gone nowhere". Voir Dovey L. et Impey A., "African Jim... », art. cité, p. 71.

${ }^{84}$ Coplan D., In Township Tonight!..., op. cit., p. 173.

85 Dovey L. et Impey A., « African Jim... », art. cité, p. 61.
} 
La voix et le charisme de Dolly Rathebe semblaient transcender les aspects idéologiques des paroles de la chanson, captivant le spectateur qu'était Themba comme ils captivaient I'acteur jouant Jim dans le film. De manière significative, cet accueil enthousiaste des films ne trouve guère sa place dans les études sud-africaines sur le cinéma. Ntongela Masilela ignore notamment ce point de vue lorsqu'il évoque le « rejet silencieux » de ce type de films par les intellectuels africains, notant pourtant que « curieusement, cependant, Todd Matshikiza a écrit avec enthousiasme sur Song of Africa, un film qui suivait le chemin ouvert par Jim Comes to Jo'burg ${ }^{86} »$. Matshikiza, qui était compositeur, pianiste et critique musical, appréciait particulièrement le fait que le film montrait « l'influence de la musique tribale africaine sur le jazz américain moderne ${ }^{87} »$.

Le second paradoxe touchant à la popularité des films «All-Africans » tient au fait qu'ils tranchaient avec le goût du public pour les récits et l'esthétique sophistiqués d'Hollywood. Outre les « textes cachées » contenus dans les paysages sonores des films ${ }^{88}$, leur succès résidait dans la force des apparitions des artistes locaux à l'écran comme le suggère Themba. On peut supposer que la réception des spectateurs de ces images et performances ambivalentes faisait passer le contenu idéologique au second plan, la scène de Dolly Rathebe oblitérant l'esthétique peu sophistiquée et l'intrigue simpliste de Jim Comes to Jo'burg. Ici, le plaisir cinématographique résidait moins dans l'esthétique visuelle que dans la possibilité d'accéder à la fiction. Loin de l'idéologie impériale qui niait aux Africains la capacité à devenir de réels spectateurs, et contrairement aux films coloniaux vidés de leur potentiel fictionnel, Jim Comes to Jo'burg était spectaculaire. Il était ostensiblement fabriqué et animé par les voix et les icônes de la scène musicale locale. Lorsque Dolly Rathebe chantait une adaptation de « / Lost My Sugar in Salt Lake City», elle faisait écho à l'interprétation de Mae E. Johnson dans Stormy Weather, et laissait ainsi la possibilité aux spectateurs d'y voir la performance de liens transatlantiques entre les scènes noires des États-Unis et d'Afrique du Sud.

De surcroît, la projection de Jim Comes to Jo'burg amplifiait l'une des dimensions essentielles du township cinématographique, à savoir sa capacité à troubler les frontières symboliques entre le cinéma et l'expérience urbaine. Dans ses mémoires, Bloke Modisane se souvient qu'à mesure que l'apartheid étendait son emprise sur son existence, « la démarcation entre la fiction [fantasy] et la réalité devenait de moins en moins perceptible ${ }^{89}$ ». L'évocation des groupes de jazz locaux d'inspiration états-unienne, tels que les Jazz Maniacs et les African Inkspots, incarnés dans le film par les musiciens de marabi-jazz jouant au club Ngoma, favorisait ce phénomène. Telle que la décrit Davis, cette performance peut en effet être vue comme une célébration de la musicalité du township :

En écoutant la musique, je pense qu'il est pratiquement impossible de dire si ces musiciens viennent d'Afrique du Sud. Leur attitude même durant la performance, jusqu'à la cigarette pendue

\footnotetext{
${ }^{86}$ Masilela Ntongela (2003), "The New African Movement and the Beginnings of Film Culture in South Africa », in I. Balseiro et N. Masilela (dir.), To Change Reels: Film and Culture in South Africa, Detroit, Wayne State University Press, p. 26. Voir aussi Ansell, G., Soweto Blues..., op. cit., p. 75.

${ }^{87}$ Masilela N., "The New African Movement... », art. cité, p. 26.

${ }^{88}$ Dovey L. et Impey A., « African Jim... », art. cité, p. 63.

${ }^{89}$ Modisane Bloke (1965), Blame Me on History, London, Panther Books, p. 175.
} 
aux lèvres de Sam Maile qui taquine les touches du piano, témoigne d'une influence les ayant séduits au point de s'y abandonner corps et âme..$^{90}$

Le personnage de Dolly Rathebe brouillait particulièrement la frontière entre réalité et fiction. Selon Don Mattera, son choix de prendre le nom de Rathebe - parce qu'« ils étaient riches et que Dolly était une beauté » - était révélateur d'« un monde de faux-semblants, un monde qui voulait aspirer à la grandeur ${ }^{91} »$. Dans le film, les acteurs l'appellent effectivement Dolly ou Judy, introduisant son nom de scène dans plusieurs passages du film².

Du point de vue des spectateurs, comme le note l'acteur sud-africain John Kani, « quand Jim Comes to Jo'burg était projeté, c'était comme un miracle. Nous voyions des Noirs dans ce film. Nous voyions des Noirs parle ${ }^{93}$ ». Les spectateurs se délectaient de la dimension visuelle et auditive/orale du film, cette dernière reflétant l'un des traits les plus symptomatiques du Johannesburg noir. La première impression du réalisateur de Come Back, Africa, Lionel Rogosin, arrivant dans cette ville en 1958, en témoigne: " [Les Africains] ressemblaient et s'habillaient d'une manière si semblable à celle des Noirs américains que j'étais stupéfait quand ils se mettaient à parler en zoulou. Cela allait complètement à l'encontre de ma perception sensorielle. C'était comme assister à un film doublé, et que personne ne parlait la bonne langue ${ }^{94} »$. Outre l'oralité locale, et probablement en raison d'un budget limité, la bande sonore comportait exclusivement des chansons sud-africaines déjà connues. Jim Comes to Jo'burg suscitait ainsi la curiosité des Sud-Africains qui pensaient que le bioscope n'était pas un endroit où les « gens décents » allaient se divertir ${ }^{95}$, aussi bien que celle des spectateurs ne fréquentant jamais les cinémas - comme le relatait la réalisatrice Erica Rutherford, " on a retourné des dizaines de spectateurs ${ }^{96}{ }^{\prime}$.

À propos de Matamata et Pilipili, les habitants de Léopoldville faisaient des commentaires similaires. Réalisées par le missionnaire belge Albert van Haelst à Luluabourg (aujourd'hui Kananga) dans les années 1950, ces comédies muettes sur les mésaventures de deux amis connaissaient un grand succès dans toute la colonie. Comme le note James M. Burns, Van Haelst produisait des films véritablement populaires car ils «transgressaient plusieurs des règles fondamentales du cinéma colonial ${ }^{97}$ ». Outre l'utilisation de trucages tels que le « stopaction » faisant disparaître les acteurs, les films étaient en noir et blanc, ce qui était alors jugé « irréaliste ». Bien que Matamata (joué par Kasongo Biembe) et Pilipili (on ignore le nom de l'acteur) ne soient jamais apparus au générique des films, une série développait pour la première fois deux personnages noirs attachants de film en film.

\footnotetext{
90 Davis P., In Darkest Hollywood, op. cit., p. 24.

91 Stein P. et Jacobson R. (dir.), Sophiatown Speaks, op. cit., p. 9

92 Dovey L. et Impey A., "African Jim... », art. cité, p. 70.

93 Davis P., In Darkest Hollywood, op. cit., p. 26. Je souligne.

94 Rogosin Lionel (2004), Come back, Africa: A Man Possessed, Johannesburg, STE publishers, p. 20.

95 Dovey L. et Impey A., "African Jim... », art. cité, p. 61.

96 Fleming, "Stars of Song and Cinema », art. cité, p. 196

97 Burns J., Flickering Shadows..., op. cit., p. 104.
} 


\section{Illustration $n^{\circ} 3$ : L'acteur Biembe Kasongo (Matamata) au travail chez Luluafilms ${ }^{98}$}

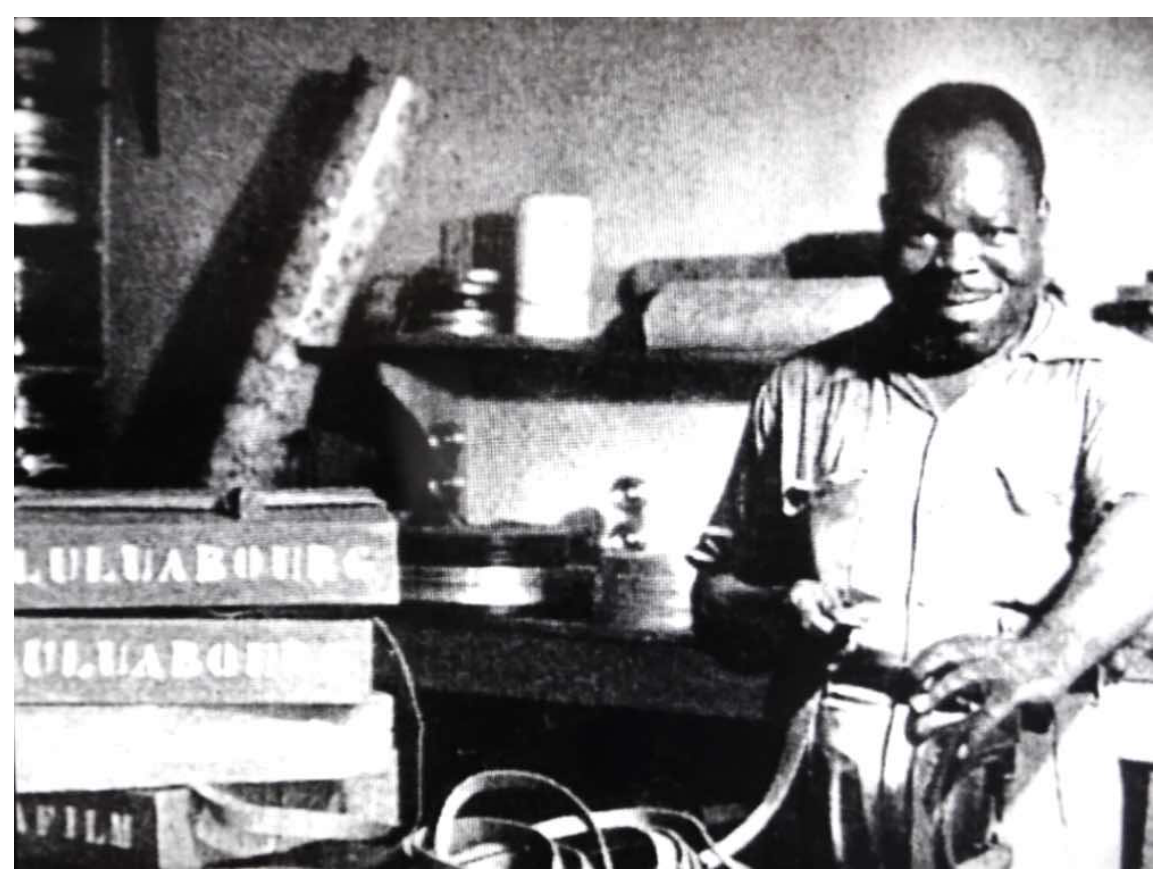

Malgré leur regard paternaliste, ces films donnaient une idée de ce qu'aurait pu être la fiction congolaise. Dans un documentaire restituant douze de ces courts métrages, des spectateurs anonymes se souviennent de la foule enthousiaste se pressant pour se rendre à la projection quand, le soir, un camion traversait la cité de Léopoldville pour annoncer Matamata et Pilipili:

C'était du cinéma, c'était une chose qui bougeait. En plus, ce qui était merveilleux, c'est que ça mettait en scène des personnes qu'on côtoyait dans la rue tous les jours, ce n'était pas des acteurs comme Alain Delon! On le voit. Je me dis, quelque part, ils ne jouent pas, ils vivent. ${ }^{99}$

Selon l'écrivain sud-africain Arthur Maimane, le passage de la vie quotidienne à l'écran émerveillaient également les Sud-Africains : en voyant « des films qui montraient des gens que tu reconnaissais, des rues familières », les spectateurs criaient : "Hey, c'est ma rue ! Je vis dans cette rue ! [...] Ils faisaient l'effet de films maison ${ }^{100} »$. Alors que les films de divertissement étaient jusqu'alors habités par des acteurs mythiques, montrant des espaces mythifiés et lointains, les spectateurs voyaient ici leur ville projetée sur un écran jusqu'alors réservé aux rêves.

La matérialité sonore de Matamata correspondait par ailleurs à la culture cinématographique locale. Ces courts-métrages muets ne comportaient aucun des commentaires didactiques censés orienter la réception du film. Seules de courtes phrases, traduites en cinq langues, précédaient chacune des scènes. De plus, les effets sonores utilisés

\footnotetext{
98 Cliché du film de T. Bourlard, Matamata et Pilipili, Belgia, Videocam, Cobra films, Centre de I'audiovisuel à Bruxelles.

99 Bourlard Tristan (1996), Matamata et Pilipili, Belgia, Videocam, Cobra films, Centre de l'audiovisuel à Bruxelles. Pour une critique de l'absence d'identification des sujets interviewés dans ce documentaire et son manque de critique vis-à-vis des propos racistes exprimés par les missionnaires, voir le compte-rendu de Sheila Petty (1999), Matamata and Pilipili, H-AfrLitCine | H-Net. En ligne. URL : https://networks.h-net.org/node/15766/reviews/16715/petty-matamata-and-pilipili (consulté le 21 juillet 2021).

100 Davis P., In Darkest Hollywood..., op. cit., pp. 26-27.
} 
étaient ceux appréciés par les aficionados des westerns. Le cinéaste utilisait des foley (effet sonore correspondant à une action) tels que des bruitages accompagnant la chute de Matamata, une fessée à un enfant, ou le sifflet des policiers congolais poursuivant Pilipili. Tandis que le réalisateur utilisait des sons diégétiques (la source sonore était toujours visible à l'écran) pour décrire l'action, la musique était le seul son extra diégétique.

\section{Illustration $n^{\circ} 4$ : Van Haelst avant l'enregistrement d'une chorale dans les studios de Luluafilms ${ }^{101}$}

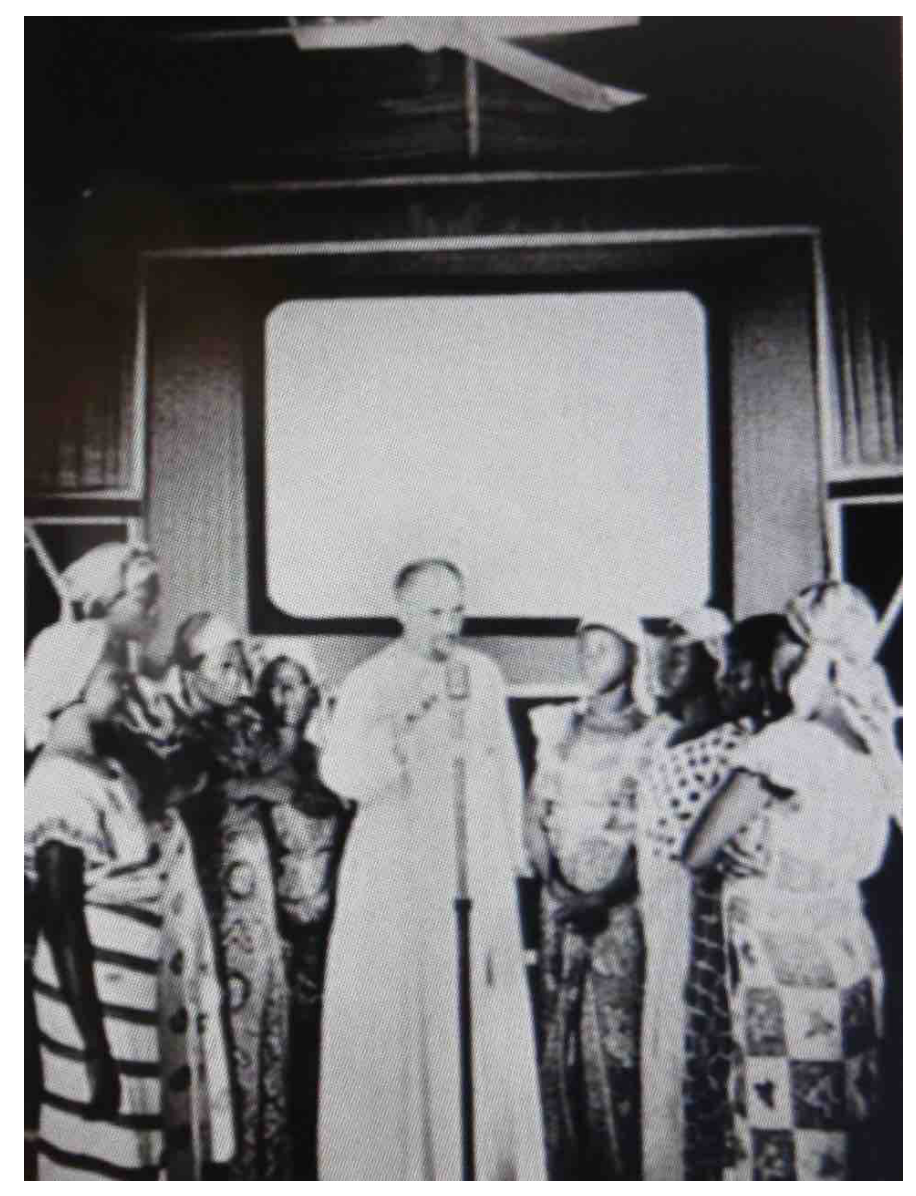

Bien que Matamata ne montre pas de musiciens, la série laissait entrevoir certains aspects de la vie musicale urbaine aux spectateurs. Un des films montre par exemple des habitants de Luluabourg dansant autour d'un phonographe ${ }^{102}$. Après deux épisodes accompagnés de musique classique, la bande sonore de Matamata est par ailleurs uniquement composée de musiques locales. Des percussions traditionnelles dominent la bande-son tandis que des compositions de cuivres et de guitares soulignent des séquences particulières, comme les course-poursuites. En ce sens, la bande-son de Matamata et Pilipili correspondait à la vision du réalisateur et historien béninois Paulin Soumanou Vieyra qui déclarait que les musiciens africains devaient créer des musiques adaptées au cinéma, des compositions " sans "vocalité" »

\footnotetext{
101 Cliché du film de T. Bourlard, Matamata et Pilipili, op. cit. 102 Ibid.
} 
pouvant participer à «la réalité cinématographique ${ }^{103}$. Faute de sources sur la bande sonore de la série, on peut seulement spéculer que Van Haelst décida d'utiliser des musiques urbaines et d'enregistrer des artistes locaux à la demande des spectateurs congolais.

L'étude des différentes modes de réception sonore des spectateurs congolais et sudAfricains témoigne de leur aspiration à contrôler l'événement cinématographique et sa diffusion dans la culture urbaine. II est clairement apparu, à cet égard, que le public de Léopoldville détournait et s'appropriait le système du commentaire en direct, produisant ainsi des récits polyphoniques se substituant aux voix linéaires du Service d'information et des missionnaires. Face aux cinéastes religieux qui cherchaient à «bannir les rêves », le public rejetait les dialogues des westerns tout en amplifiant la panoplie sonore du cow-boy, avant de la propager dans la rue. Comme l'indique l'argot urbain avec la métaphore de « bande sonore » désignant l'auteur d'un discours interminable ${ }^{104}$, ce que j'ai appelé «l'urbanité sonore » existait bien au-delà du monde de la musique et résultait des liens multiples entre l'écoute quotidienne et la politique de la fiction.

À Sophiatown, les correspondances entre les paysages sonores de la ville et les composantes audibles des films hollywoodiens mettent en évidence les lignes floues entre la fiction cinématographique et la réalité urbaine. Plus qu'ailleurs en Afrique, les habitants de Sophiatown ont imprégné la vie urbaine de fiction en transformant le township en un lieu où l'on peut apprendre comment « vaincre les intentions du monde à [son] égard ${ }^{105}$ ». Ces modes de réception sonore des films, en particulier l'usage des dialogues, montrent comment les sons médiatisés par le cinéma et d'autres technologies, discours et épistémologies locales, façonnaient les espaces et les luttes urbaines.

En Afrique du Sud et au Congo belge, la ségrégation et la censure visaient à empêcher le public africain d'utiliser les potentialités subversives du cinéma et, ce faisant, produisaient une expérience sensorielle des médias marquée par des interférences, des fragments de discours coloniaux et missionnaires et des traces de coupes censurées ${ }^{106}$. Dans ce contexte, la possibilité de voir l'urbanité sonore et les townships reflétés dans les premiers films mettant en scène des acteurs africains marqua un tournant décisif à la fin des années 1940. Avec Jim comes to Jo'burg et Matamata et Pilipili, de nouvelles possibilités s'offraient aux spectateurs et complexifiaient le township cinématographique. Les habitants de Sophiatown pouvaient en particulier apprécier l'art de la chanteuse Dolly Rathebe qui subvertissait les distorsions du primitivisme lorsqu'elle apparaissait dans ce prestigieux médium.

Une attention particulière portée au rôle historique joué par l'événement cinématographique est donc utile pour comprendre les expériences africaines de la ségrégation, notamment la manière dont le développement des cultures politiques impliquait une imbrication des plaisirs et des stratégies. Les similitudes et les différences entre les

\footnotetext{
103 Vieyra Paul (1975), Le Cinéma africain : des origines à 1973, Paris, Présence africaine.

104 Sesep N., Langage, normes..., op. cit., p. 40.

105 Baldwin J., "The Devil Finds Work », art. cité, p. 483.

106 Pour un autre exemple, voir l'analyse de Larkin de l'esthétique et des distorsions sonores des vidéos piratées au Nigeria dans Signal and Noise..., op. cit., pp. 217-242.
} 
événements cinématographiques et les villes examinées dans cet article pourraient être enrichies par l'analyse d'autres modes de réception des films à la fin de l'époque coloniale. Des recherches sur les villes où la danse semblait dominer la réception performative des films comme Dar es Salaam, en Tanzanie, et Elisabethville, au Congo belge (aujourd'hui Lubumbashi), approfondiraient notre compréhension de la politique du son et de la fiction dans les townships africains.

Charlotte Grabli

CIRESC-CNRS (France) / Département d'histoire de UCLA (États-Unis)

\section{Bibliographie}

Altman Rick (1992), Sound Theory, Sound Practice, London; New York, Psychology Press.

Ambler Charles (2001), "Popular Films and Colonial Audiences: The Movies in Northern Rhodesia », The American Historical Review, 106(1), pp. 81-105.

Ansell Gwen (2004), Soweto Blues: Jazz, Popular Music, and Politics in South Africa, New York, Continuum.

BALANDIER Georges (1985 [1955]), Sociologie des Brazzavilles noires, Paris, Armand Colin.

BALDWIN James (1998 [1976]), «The Devil Finds Work », in T. MoRrIson (dir.), Collected Essays, New York, Literary Classics of the United States, pp. 477-576.

BARBER Karin (1987), «Popular Arts in Africa », African Studies Review, 30(3), p. 1-78.

BICKFORD-SMITH Vivian (2006), "How Urban South Africa Life Was Represented in Film and Films Consumed in South African Cities in the 1950s », Journal of Interdisciplinary Crossroads, 2(3), pp. 431442.

BOtTOMORE Stephen (2001), "The Story of Percy Peashaker: Debates about Sound Effects in the Early Cinema ", in R. Abel et R. Altman (dir.), The Sounds of Early Cinema, Bloomington, Indiana University Press, pp. 129-142.

BOUCHARD Vincent, LACASSE Germain et SCHEPPLER Gwenn (2009), «Présentation. L'interrègne : I'héritage des bonimenteurs ", Cinémas: revue d'études cinématographiques / Cinémas: Journal of Film Studies, 20(1), pp. 7-21.

BouCHARD Vincent (2010), «Commentary and Orality in African Film Reception », in M. Saul et R. Austen (dir.), Viewing African Cinema in the Twenty-First Century: Art Films and the Nollywood Video Revolution, Athens, Ohio University Press, pp. 95-107.

BouRlard Tristan (1996), Matamata et Pilipili, Belgia, Videocam, Cobra films, Centre de l'audiovisuel à Bruxelles.

BURNS James (2002), Flickering Shadows: Cinema and Identity in Colonial Zimbabwe, Athens, Ohio University Press.

CAPELLE Emmanuel (1947), La cité indigène de Léopoldville, Élisabethville, CEPSI.

CHION Michel (1999), The Voice in Cinema, New York, Columbia University Press. 
Clarke David B. (dir.) (1997), The Cinematic City, London, New York, Routledge.

CONVENTS Guido (2006), Images \& démocratie: les Congolais face au cinéma et à l'audiovisuel: une histoire politico-culturelle du Congo des belges jusqu'à la République démocratique du Congo (18962006), Kessel-Lo, Afrika Film Festival.

Coplan David B. (2007), In Township Tonight!: Three Centuries of South African Black City Music and Theatre, Auckland Park, Jacana Media.

CORRIOU Morgan (2010), " Hourras, "hou hou" et tohu-bohu dans les cinémas de Tunisie à l'époque du protectorat », in O. CARLIER (dir.), Images du Maghreb, Images au Maghreb (XIX $-x x^{e}$ siècles). Une révolution du visuel ?, Paris, L'Harmattan, pp. 203-236.

Davis Peter (1996), In Darkest Hollywood: Exploring the Jungles of Cinema's South Africa, Athens, Ohio University Press.

DOVEY Lindiwe et IMPEY Angela (2010), « African Jim: Sound, Politics, and Pleasure in Early "Black" South African Cinema », Journal of African Cultural Studies, 22(1), pp. 57-73.

FAIR Laura (2018), Reel Pleasures: Cinema Audiences and Entrepreneurs in Twentieth-Century Urban Tanzania, Athens, Ohio University Press.

FLEMING Tyler (2012), "Stars of Song and Cinema: The Impact of Film on 1950s Johannesburg's Black Music Scene », in T. Falola et T. Fleming (dir.), Music, Performance and African Identities, New York, Routledge, pp. 169-190.

FOREST Claude (2021), « Les films à l'affiche dans les salles africaines Secma-Comacico (1960-1961) », Revue d'histoire contemporaine de l'Afrique, 1, en ligne. URL: https://oap.unige.ch/journals/rhca/article/view/01.forest (consulté le 4 août 2021).

GABBARD Krin (1996), Jammin' at the Margins: Jazz and the American Cinema, Chicago, University of Chicago Press.

Goerg Odile (2015), Fantômas sous les tropiques: aller au cinéma en Afrique coloniale, Paris, Vendémiaire.

Gondola Charles-Didier (2014) «Popular Music, Urban Society, and Changing Gender Relations in Kinshasa, Zaire (1950-1990) » in M. Grosz-NGATE et O. Kokole (dir.), Gendered Encounters: Challenging Cultural Boundaries and Social Hierarchies in Africa, New York, Routledge, pp. 65-84.

(2016), Tropical Cowboys: Westerns, Violence, and Masculinity in Kinshasa, Bloomington, Indiana University Press.

GRABLI Charlotte (2019), «La ville des auditeurs : radio, rumba congolaise et droit à la ville dans la cité indigène de Léopoldville (1949-1960) », Cahiers d'études africaines, 233(1), pp. 9-45.

HAFFner Pierre (1978), Essai sur les fondements du cinéma africain, Abidjan, Nouvelles Éditions Africaines.

HEBDIGE Dick (2008), Subculture: The Meaning of Style, London, New York, Routledge.

LARKIN Brian (2008), Signal and Noise: Media, Infrastructure, and Urban Culture in Nigeria, Durham, Duke University Press.

MAINGARD Jacqueline (2007), South African National Cinema, London, Routledge. 
Majumbdar Neepa (2001), "The Embodied Voice: Song Sequences and Stardom in Popular Hindi Cinema ", in P. WoJCIK et A. KNIGHT (dir.), Soundtrack Available: Essays on Film and Popular Music, Durham, Duke University Press, pp. 161-182.

Martin Denis-Constant (2008), "Our Kind of Jazz : musique et identité en Afrique du Sud », Critique internationale, 38(1), pp. 91-110.

MASILELA Ntongela (1991), " "Come Back Africa" and South African film history », Jump Cut: a Review of Contemporary Media, 36, pp. 61-65.

(2003), « The New African Movement and the Beginnings of Film Culture in South Africa », in I. BALSEIRO et N. MASILELA (dir.), To Change Reels: Film and Culture in South Africa, Detroit, Wayne State University Press, pp. 15-30.

Metz Christian (1977), Le signifiant imaginaire: psychanalyse et cinéma, Paris, Union générale d'éditions.

ModisANe Bloke (1965), Blame Me On History, London, Panther Books.

Molel Kolonga (1979), Kinshasa, ce village d'hier, Kinshasa, Sodimca.

MPHAHLEle Ezekiel (1978), Down Second Avenue, Gloucester, Peter Smith.

NixON Rob (1994), Homelands, Harlem, and Hollywood, London, New York, Routledge.

OtTEN Rik et BACHY Victor (1984), Le cinéma dans les pays des grands lacs : Zaïre, Rwanda, Burundi, Paris, L'Harmattan.

PetTY Sheila (1999), Matamata and Pilipili, H-AfrLitCine | H-Net. En ligne, URL : https://networks.hnet.org/node/15766/reviews/16715/petty-matamata-and-pilipili (consulté le 21 juillet 2021).

RamiRez Francis et Rolot Christian (1985), Histoire du cinéma colonial au Zaïre, au Rwanda et au Burundi, Bruxelles, Musée royal de l'Afrique Centrale.

RICE Tom (2016), «'Are You Proud to Be British?': Mobile Film Shows, Local Voices and the Demise of the British Empire in Africa », Historical Journal of Film, Radio and Television, 36(3), pp. 331-351.

Rogosin Lionel (2004), Come back, Africa: a Man Possessed, Johannesburg, STE publishers.

RouCH Jean (1958), "L'Africain devant le film ethnographique », in Rencontres internationales «Le cinéma et l'Afrique au sud du Sahara » à l'Exposition universelle de Bruxelles, pp. 92-94.

SAnsot Pierre (2004), Poétique de la ville, Paris, Payot \& Rivages.

SCOHY André (1958), «L'action du gouvernement général du Congo belge dans l'éducation des masses par le cinema ", in Rencontres internationales "Le cinéma et l'Afrique au sud du Sahara » à l'Exposition universelle de Bruxelles, pp. 76-78.

SESEP N'Sial Bal-Nsien (1990), Langage, normes et répertoire en milieu urbain africain : l'indoubill, Quebec, Laval University.

StANField Peter (2002), Horse Opera: The Strange History of the 1930s Singing Cowboy, Urbana, University of Illinois Press.

SteIn Pippa et JACOBSON Ruth (dir.) (1986), Sophiatown Speaks, Johannesburg, Junction Avenue Press. 
VAN Den Heuvel Alexandre (1958), "Convient-il de faire du "film pour Africains"? ", Rencontres internationales « Le cinéma et l'Afrique au sud du Sahara » à I'Exposition universelle de Bruxelles.

VAN SChuYlenbergh Patricia (2021), "Le Congo belge sur pellicule: Ordre et désordres autour d'une décolonisation (ca. 1940- ca. 1960) », Revue d'histoire contemporaine de l'Afrique, 1, en ligne. URL: https://oap.unige.ch/journals/rhca/article/view/01.vanschuylenbergh (consulté le 4 août 2021).

VIEYRA Paul (1975), Le Cinéma africain : des origines à 1973, Paris, Présence africaine.

VILAKAZI Absolom (1965), Zulu Transformations: A Study of the Dynamics of Social Change, Pietermaritzburg, University of Natal Press.

WRIGHT Richard (2008 [1954]), Black Power: A Record of Reactions in a Land of Pathos, New York, Harper \& Brothers. 